\title{
DEVELOPING AS-BUILT BIM MODEL PROCESS MANAGEMENT SYSTEM FOR GENERAL CONTRACTORS: A CASE STUDY
}

\author{
Yu-Cheng LIN ${ }^{\mathrm{a}}$, Hsin-Yun LEE ${ }^{\mathrm{b}}$, I-Tung YANG ${ }^{\mathrm{c}}$ \\ ${ }^{a}$ Department of Civil Engineering, National Taipei University of Technology, No. 229, \\ No. 1. Chung-Hsiao E. Rd., Sec. 3, Taiwan \\ ${ }^{b}$ Department of Civil Engineering, National Ilan University, No. 1, Section 1, Shennong Road, \\ I-Lan City, Taiwan \\ ${ }^{c}$ Department of Construction Engineering, National Taiwan University of Science and Technology, \\ No. 43, Section 4, Keelung Road Taiwan
}

Received 10 Jan 2013; accepted 03 Jul 2013

\begin{abstract}
As the application of building information modeling (BIM) becomes more common, BIM model management becomes necessary and important to enhance the effectiveness of BIM implementation for a general contractor (GC) during the construction phase. Implementation of BIM models in the construction phase, which typically involves participants from different fields, often has numerous BIM-related interfaces and problems. Therefore, feedback from the most recent as-built model tracking and BIM model problems are essential for BIM process management (BIM PM) in the construction field. BIM PM has become the most important aspect of a sound as-built BIM model management strategy. Changes in as-built BIM models should be identified, updated, and tracked for BIM PM, such that version management of as-built BIM models can be improved, while minimizing rework and reducing as-built BIM models development duration. Systematic approaches and information on management platforms for enhancing BIM PM during the construction phase are lacking. This study proposes a novel approach to the BIM model management which is to manage and track all versions of as-built BIM models. The primary purpose of this study is to develop a web Construction BIM-based PM (ConBIM-PM) system to enhance a General Contractor's ability to share BIM PM information and track construction projects more efficiently. The ConBIM-PM system provides users with a centralized storage of all versions of as-built models during the construction phase of a project so that they are able to track and manage the current status of modified as-built models and BIM PM information effectively. Finally, the ConBIM-PM system is applied to a case study of a building project in Taiwan to verify its efficacy and demonstrate its effectiveness. The case study results show that the ConBIM-PM system is effective for BIM PM work by a GC during the construction phase of the BIM implementation.
\end{abstract}

Keywords: BIM, process management, building information modeling, information system, web-based system, BIM management.

\section{Introduction}

Building information modeling (BIM) is a new industry term that refers to parametric 3D computer-aided design (CAD) technologies and processes in the architecture, engineering and construction (AEC) industry (Taylor, Bernstein 2009). During the construction phase, BIM engineers and managers, typically from the general contractor (GC), execute BIM-related work but rarely share updated change information about as-built BIM models (abbreviated as as-built models in this paper) with other project and BIM engineers. Tracking and managing version information for as-built models effectively can improve BIM process management (BIM PM) in construction, thereby eliminating mistakes. Effectively sharing version information allows project engineers to identify existing as-built models and to apply accurate as-built models. Without BIM PM, poorly coordinated and controlled boundary conditions among project engineers can cause management problems, coordination difficulties, and mismatched as-built models.

During the implementation of BIM management in practice, as-built models usually undergo change and update for various reasons. Change information is generally not shared effectively between service providers, or BIM engineers and project engineers. Moreover, project engineers frequently execute their own work rarely reporting change information of the as-built models to BIM engineers. In general, e-mail is the most practical method used by engineers to communicate and respond to changes in as-built models during the construction phase. Despite the many studies and discussions in academic and practical literature, systematic approaches and information platforms are lacking for managing changes and problems in as-built models during the construction

Corresponding author: Yu-Cheng Lin

E-mail:yclin@ntut.edu.tw 
phase. BIM PM is currently a major problem in onsite BIM implementation because no appropriate platforms exist to assist project and BIM engineers in tracking and managing change information of as-built models during the construction phase.

Notably, change information of as-built models is an information-intensive task in which extremely useful information is made available to BIM managers, BIM engineers, and project engineers. Conventional BIM-related communication methods, such as e-mail, may not effectively track and share BIM PM with others. In order to assist BIM managers and engineers in exchanging and sharing information on changes in asbuilt models, the primary objective of this study is to facilitate the sharing and management of changes and updates of as-built models for the GC during the construction phase. Furthermore, this study is to facilitate an approach and platform for updating as-built models based on feedback from project engineers. In order to assist the GC to effectively implement BIM work onsite, this study develops the ConBIM-PM system for engineers to enhance information for BIM model sharing and tracking. The main function of the BIM PM approach in this study is to enhance the tracking and updating change information for as-built models. The BIM PM approach retains changes to as-built models information in a digital format and facilitates easy updates and transfer of changes to information in the web environment. By using the ConBIM-PM system, project engineers and BIM engineers can obtain an overview of past and current as-built model update information for a given project. Furthermore, project engineers can access and utilize the most recent updates of as-built models during their construction phase. The changes and problems with the as-built models can be available to each project engineer via the markup-enabled as-built models. This research is a pilot study that applies the ConBIM-PM system for BIM PM work during a building project in Taiwan and analyzes and discusses the entire BIM PM work.

\section{Literature review}

$\mathrm{BIM}$ is one of the most promising recent developments in the AEC industry (Azhar 2011). BIM was introduced nearly ten years ago to provide an environment where any related information on $3 \mathrm{D}$ entity models could be retrieved during the project life cycle (Tse et al. 2005; Ding et al. 2012). BIM is a digital tool that supports continual updating and sharing of project design information (Gould, Joyce 2008), and contains precise geometry and relevant data needed to support the design, procurement, fabrication, and construction activities to describe 3D object-oriented CAD (Eastman et al. 2008). BIMbased visualization can express information more intuitively (Ding et al. 2012). It is believed to be essential in AEC to manage, share, and exchange information among project stakeholders, such as architects, engineers, contractors, owners and subcontractors (Fu et al. 2006). BIM assists construction planners in making crucial decisions by enabling visualization of the details of the prospective work (Chau et al. 2004). While several definitions of BIM are proposed in prior research, the National Building Information Modeling Standard Committee defines a building information model (BIM) as "a digital representation of physical and functional characteristics of a facility. As such, it serves as a shared knowledge resource for information about a facility forming a reliable basis for decisions during its lifecycle from inception onward" (National Building Information Modeling Standard 2007). BIM digitally contains precise geometry and relevant data needed to support the design, procurement, fabrication, and construction activities to describe 3D object-oriented CAD (Eastman et al. 2008). BIM is an additional model for an engineering information database, storing all the architectural designs with geometric information and the corresponding technical information of all the works (Ding et al. 2012). BIM supports the automatic evaluation of a building design, rather than the manual, iterative, and time-consuming evaluation of CAD drawings (Lee et al. 2012c). BIM modeling enables the users to generate and update project documents automatically, and building information data are attached to the elements (Eastman et al. 2008).

BIM is a new technology in the field of CAD and contains not only geometric data, but also a great amount of engineering data collected throughout the lifecycle of a building (Xudong, Jie 2007). It is a new industry term referring to parametric $3 \mathrm{D}$ computer-aided design (CAD) technologies and processes in the AEC industry (Taylor, Bernstein 2009). BIM is a digital tool that supports continual updating and sharing of project design information (Gould, Joyce 2008), and is a computable representation of all of a building's physical and functional characteristics and related lifecycle information. It also serves as a repository of information for building owners and operators and is used and maintained throughout the lifecycle of a building (Manning, Messner 2008). BIM has three main features. The first feature is that data and information about models can be stored in databases to facilitate collaboration. The second feature is that changes to these databases can be managed, such that a change in a database affects all other parts of models. The third feature is that information from a particular model can be captured and preserved for reuse by adding industry-specific applications (Vanlande et al. 2008). A BIM system enables users to integrate and reuse building information and domain knowledge throughout the lifecycle of a building (Eddy, Bradley 2008).

Much previous research has examined BIM issues in construction. There are many core benefits, barriers, frameworks, and recommendations for usage of BIM in supporting decisions and improving processes throughout the lifecycle of a project (Tse et al. 2005; NBIMS 2007; 
Eastman et al. 2008; Shen, Issa 2010; Manning, Messner 2008; Succar 2009; Becerik-Gerber, Kensek 2010; Becerik-Gerber, Rice 2010; Jung, Joo 2011; Barlish, Sullivan 2012). Related to the design phase of a project, these topics include parametric modeling, BIM at different Level of Development (LOD), identification of design conflicts and analysis, green design, design simulation, cost estimation, and accurate geometric representation of all facilities (Li et al. 2006; Leite et al. 2011; Eastman et al. 2008; Kaner et al. 2008; Shen, Issa 2010; Staub-French, Khanzode 2007; Manning, Messner 2008; Fox, Hietanen 2007; Schlueter, Thesseling 2009; Umit, Jason 2010; Shen et al. 2012; Lee et al. 2012a, 2012b, 2012c; Redmond et al. 2012). During the construction phase, these benefits include less rework, reduced requests for information and change orders, improved customer satisfaction through visualization, improved productivity in phasing and scheduling, faster and more effective construction management with easier information exchange, accurate cost estimation, and better visualization for safety analysis (Eastman et al. 2008; Goedert, Meadati 2008; Hardin 2009; Matta, Kam 2010; Dossick, Neff 2010; Elbeltagi, Dawood 2011; Azhar 2011; Zhou et al. 2012; Ren et al. 2012; Hartmann et al. 2012). During the operation phase, these benefits include control of the facilities management process, integrated lifecycle data, rapid and accurate information on update and change activities, and more effective facility management with easier information exchange (Eastman et al. 2008; Hardin 2009; Staub-French, Khanzode 2007; Manning, Messner 2008; Jason, Umit 2010; CRC... 2010; Klein et al. 2012).

The effective management of construction drawing (e.g. traditional 2D drawing) is an important provision in the design and construction process when the number of drawings is hundreds or thousands (Shih 1994). Furthermore, the control and management of 2D drawings is an important approach that enables organizations to securely publish, store and deliver 2D drawings by the effective communication platforms. Previously, many commerce electronic drawing management systems or software were developed and utilized widely by the $\mathrm{A} / \mathrm{E} / \mathrm{C}$ industry. Those drawing management systems were utilized to organize, distribute, standardize and control the process of 2D drawings managed for the construction projects. Furthermore, there are many 2D drawing control information systems developed to capture, organize, extract meaningful information, and store drawings efficiently in a centralized repository.

Despite many articles and system developments in academic and practice literature, there is a lack of systematic approaches and BIM PM platforms for tracking and managing as-built models work and for solving updated problems during the construction phase. To solve this problem, this study proposes a novel mechanism for BIM model management to manage all as-built BIM models and to track communication of BIM work process.

\section{Research method}

According to survey results of a questionnaire on BIM PM problems encountered during the construction phase in Taiwan (Lin 2010), the primary BIM PM problems encountered during the construction phase of a project are: (1) insufficient platforms and functions for supporting BIM PM work for construction BIM management; (2) failure to properly update changes and manage new versions of as-built models; (3) an ineffective BIM PM mechanism for tracking and managing as-built models during the construction phase; (4) no official and complete record of BIM PM work and communication among BIM-related participants; (5) few suitable platforms to assist project engineers in sharing BIM PM information when needed; and (6) difficulty tracking BIM PM work and obtaining information about BIM problems from onsite project engineers. Therefore, the main purpose for conducting this research is to develop the ConBIM-PM system to provide users with centralized storage for all versions of as-built models during the construction phase of a project, so that users can track and manage up-todate statuses of modified as-built models and BIM PM information effectively. Finally, the proposed ConBIMPM system is applied to a case study of a building project in Taiwan to verify its efficacy and demonstrate its BIM PM effectiveness.

Most concepts and contents of a non-BIM as-built model (e.g. traditional 2D drawing) process management and a BIM as-built model process management are the same. For example, the version management of the nonBIM as-built model and of the BIM as-built model is the same. The version information regarding the non-BIM and the BIM as-built model should be recorded and managed effectively. Furthermore, the changed content and information should be managed and shared with related participants effectively. However, the main difference in contents between the non-BIM and BIM as-built model process management is that the communication of a BIM as-built model is more difficult than that of a non-BIM as-built model in reviewing process management. Usually, most non-BIM as-built model process management can be done directly at the jobsite. However, the process management of the BIM as-built model is especially necessary when considering integration and communication between BIM engineers in the main office and project engineers at the jobsite. Otherwise, there would be problems with mismatch and inconsistencies in the as-built models.

Although there are many existing tools for as-built BIM model management (e.g. Autodesk Glue, ProjectWise, and Ecodomus commerce software), the software is mainly designed and developed for storing different versions of as-built models. Furthermore, some BIM software, such as Solibri, provides as-built model version comparison functionalities. Few systems are developed for communication and process management in creating 
and updating as-built models. The proposed system is developed for communication and process management of as-built models between the main office and the jobsite. This proposed management enhancement is different from other existing BIM tools and software.

BIM change management is an organizational process aimed at helping related participants to receive core information of changes in the BIM work. Thru the effective change management of the as-built models, the BIM PM work will minimize change impacts, such as reworks and model inconsistency, affecting BIM engineers and project engineers. In the BIM PM work, BIM change management refers to a BIM work process wherein changes to a project are formally introduced and approved.

Version management of the as-built model during the construction phase is now recognized as the most critical strategy for successful BIM management. Usually, project engineers need to check which as-built model is the newest version when they utilize an as-built model. However, in Taiwan, most BIM models are created and managed at the main office. Also, project engineers utilize as-built models directly at the jobsite. Therefore, the versions management mechanism of the as-built models is developed to enhance the performance of the as-built models versions management between the main office and the jobsite. The mechanism is developed based on interview results from BIM managers, BIM engineers, and project engineers. The mechanism of the as-built models versions management includes as-built models change management and as-built models feedback management. The mechanism of as-built models change management includes the as-built models published announcement and processed record of different as-built models versions. Furthermore, the mechanism of the as-built models feedback management includes the process record of the as-built models problem feedback from project engineers and process record of as-built models problem respond feedback from BIM engineers. Both mechanisms are designed and developed based on interviews and discussion with BIM engineers and project engineers.

This study focuses on the practical implementation of as-built models for the $\mathrm{GC}$ at a jobsite. In order to enhance the version management of as-built models, the proposed BIM PM procedure encompasses creating, proofing, utilizing, modifying, and completing BIM models based on interviews with construction BIM professionals. Each phase is outlined briefly as follows (Table 1).

In this study, the proposed ConBIM-PM system facilitates BIM PM work during the construction phase. In order to let the BIM manager, BIM engineers, and project engineers track the BIM PM work, the study proposed five types of process statuses for tracking asbuilt models work in the ConBIM-PM system. The five types of process statuses include processing status, pending status, proofing status, utilizing status, and finalized status. Table 2 shows the description of each BIM PM process status.
Table 1. Description of each BIM PM phase during the construction phase

\begin{tabular}{ll}
\hline Phase & \multicolumn{1}{c}{ Description } \\
\hline $\begin{array}{l}\text { Creating BIM } \\
\text { models }\end{array}$ & $\begin{array}{l}\text { Handles the initial and developing work } \\
\text { of BIM models. }\end{array}$ \\
\hline $\begin{array}{l}\text { Proofing BIM } \\
\text { models }\end{array}$ & $\begin{array}{l}\text { Confirms the accuracy of BIM model } \\
\text { before the completed BIM models } \\
\text { are ready to be published to project } \\
\text { engineers. }\end{array}$ \\
\hline $\begin{array}{l}\text { Utilizing BIM } \\
\text { models }\end{array}$ & $\begin{array}{l}\text { Application of BIM to a construction } \\
\text { project. }\end{array}$ \\
\hline $\begin{array}{l}\text { Modifying BIM } \\
\text { models }\end{array}$ & $\begin{array}{l}\text { Requesting BIM modification and BIM } \\
\text { updating processes if the BIM needs } \\
\text { changes or updates. }\end{array}$ \\
\hline $\begin{array}{l}\text { Completing BIM } \\
\text { models }\end{array}$ & $\begin{array}{l}\text { Final confirmation of a BIM model } \\
\text { without further modification or change. }\end{array}$ \\
\hline
\end{tabular}

Table 2. Description of each process status of BIM PM

\begin{tabular}{lll}
\hline Status & $\begin{array}{r}\text { Light } \\
\text { color }\end{array}$ & \multicolumn{1}{c}{ Description } \\
\hline Processing & Green & Initial BIM model creation. \\
\hline Pending & Red & $\begin{array}{l}\text { Indicates that a request has not been } \\
\text { responded to or processed in the } \\
\text { assigned time. }\end{array}$ \\
\hline Proofing & Yellow & $\begin{array}{l}\text { BIM model proofing and } \\
\text { confirmation by BIM manager. }\end{array}$ \\
\hline Utilizing & Blue & $\begin{array}{l}\text { Use of BIM model during } \\
\text { construction work. }\end{array}$ \\
\hline Finalized & Black & $\begin{array}{l}\text { Indicates that BIM model is finalized } \\
\text { and requires no further revision. }\end{array}$ \\
\hline
\end{tabular}

Figure 1 shows the concept of the proposed ConBIM-PM system. The main participants of the asbuilt BIM process will include the BIM manager and BIM engineers in the main office, and all project engineers at the jobsite (Fig. 1). Through the ConBIM-PM system, centralized management of all as-built models and related information can be tracked, downloaded, communicated, and managed among related participants in the web environment. Furthermore, project engineers may utilize the ConBIM-PM system to request as-built model updating or report as-built model problem feedback to BIM engineers through the ConBIM-PM system.

Based on communication with BIM engineers and BIM manager, the requirements of system design are as follows: (1) allows BIM engineers to illustrate and share updated or modified as-built models to project engineers; (2) allows BIM engineers to update latest status of all as-built models processes to related project engineers; (3) allows BIM engineers involved in the BIM work to be aware of the whole BIM PM process; (4) allows BIM engineers to record maintained as-built model history and comments for all revisions; and (5) allows BIM engineers to transmit the latest as-built model revisions to project engineers. 


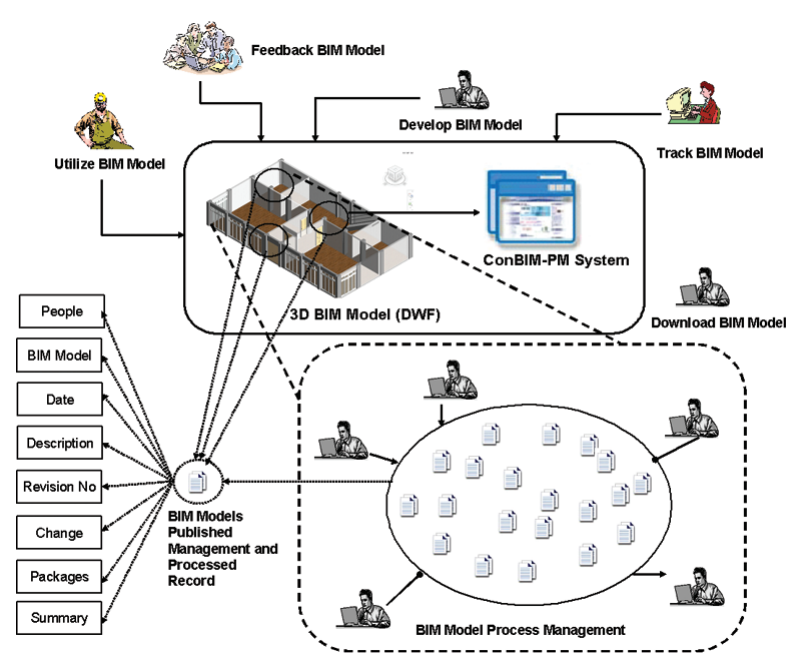

Fig. 1. The concept and framework of the proposed BIM PM approach

Based on project engineers, the requirements for system designs are as follows: (1) track as-built model versions that are stored in the system; (2) assist project engineers to edit related problems or requests associated with various as-built models; (3) provide automated identification of recipients for notification of as-built model revisions; (4) allow project engineers to access and utilize the most recent as-built models for BIM application in practice; and (5) provide project engineers with the updated or feedback content of an as-built model using markup-enable DWF file.

The system is developed based on all requirements of BIM engineers, BIM manager, and project engineers. The as-built model revision is quite common on a project with BIM application and it is not un-common for an as-built model to go through several revisions. Therefore, it is important to have a central repository that shows only the latest as-built model revision. The as-built models register acts as a central repository for all incoming as-built model revisions in the system. The as-built model revisions are classified according to projects and disciplines in the as-built model register. The ConBIM-PM system is designed and developed to automatically maintain only the latest as-built model revisions in its master document register. It also makes it easy to transmit the latest as-built model revisions to related project engineers. Before any as-built model can be issued for construction, it needs to go through a process. Normally, the as-built model must be internally reviewed and confirmed before it can be distributed for approval. When the revisions have been completed, it is up to the BIM manager to decide whether to approve or reject the as-built model. If it is rejected, the as-built model is sent back to the originator (BIM engineer), who then has to revise it and re-submit it for approval.

In order to enhance the performance of the BIM PM work, there are six forms and sheets used in the system which are: the PM sheet, PM checklist, identified problem form, an RFI (Request for Information) form, an RFI Reply sheet, and a revisions sheet (Fig. 2). Figure 2 illustrates the relationship concepts between the BIM PM forms and the as-built models. With the assistance of the BIM PM forms, the BIM PM work will be managed and tracked effectively in regards to each as-built model. The PM sheet edited by BIM engineers describes the basic information of the BIM model. The sheet includes the name of the BIM model, the version of the as-built model, a brief description of the as-built model, modeling time, and the name of the BIM engineer. The PM checklist is a form to be used by the BIM manager to handle as-built models correctly during inspection. The checklist contains the name of the as-built model, the version of the as-built model, the validated description of the as-built model, the validation time for the as-built model, and an as-built model verifier. The Identified Problem Form is used by the project engineer to respond to problems identified in the as-built models. The form includes the name of the as-built model, problem descriptions related to the problems identified in the as-built model, the proposed time, the name of the project engineer, and the marked-up as-built model with identified problems. The RFI form is used to confirm the interpretation of a detail, specification, or note on the as-built model or to secure from the BIM engineer a documented directive or clarification that is needed to continue work. The form includes the name of the as-built model, the RFI contents, time, submitter's name, and RFI attachments. The RFI reply sheet is used by the BIM engineer to reply to unclear as-built models. The sheet includes the name of the marked-up as-built model, the description of unclear elements in the as-built model or the model supplemented modeling, RFI reply contents, RFI reply time, the responder's name, and BIM-related attachments. The revisions sheet is used by BIM engineers to record revisions on as-built models to illustrate major change information. The major purpose of the sheet is to view the differences between as-built models revisions filed. The sheet includes the name of the revised as-built model, a detailed description of the modified as-built model, the updated time, the version of the revised as-built model, the name of BIM modeller (BIM engineer), and the BIM model verifier.

The BIMs Managing and Track Table is used to let the BIM manager, BIM engineers, and onsite engineers track and access the updated status of all as-built models, current versions of the as-built models, as well as the updated time of all as-built models. The proposed BIM management dashboard is designed for construction BIM PM. The BIM management dashboard can be defined as a graphic representation of the BIM PM work based on the BIM PM status. The BIM management dashboard is designed to be easily integrated with the BIM PM work and graphic representation. Integrated 


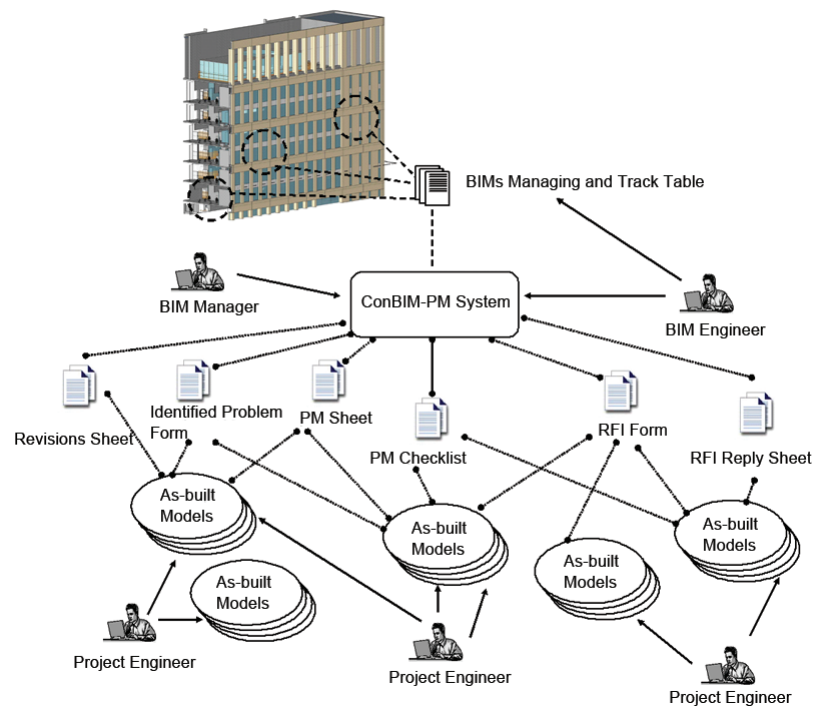

Fig. 2. Concept of BIM PM work for GC during the construction phase

with the dashboard, BIM PM Information can be identified, tracked, and managed, and problems encountered during construction projects can be resolved. The most recent updated status and current versions of all as-built models can be shared with the BIM manager, BIM engineers, and project engineers for efficient management and future reference.

Finally, a Design Web Format (DWF) file is selected as the format of the BIM file for markup use. The DWF is a secure file format developed by Autodesk for the efficient distribution and communication of rich design data for anyone who needs to view, review, or print design files. As the size of BIM models become larger, the BIM models slow down the system performance. Therefore, it is better to decompose whole BIM models into small decomposed BIM models and be exported as separate DWF file for system performance. The ConBIM-PM system provides the original as-built model (editable) and DWF file (model read only) to project engineers in order to utilize the as-built model application directly. The project engineers can use the original as-built model for advanced analysis, such as $4 \mathrm{D}$ application or collision detection. The project engineers may use the DWF file directly if they just want to review the as-built model for 3D discussion or communication. The following will describe the implementation of the system description.

\section{System implementation}

\subsection{System architecture}

The following section describes the development of the proposed ConBIM-PM system. The developed ConBIMPM system runs on Microsoft Windows 2003 software with an Internet Information Server (IIS) as the web server. The ConBIM-PM system is developed using Java Server Pages (JSPs), which are easily incorporated with
HTML and JavaScript technologies. The ConBIM-PM system server supports four distinct layers: interface, access, application, and database layers (Fig. 3). Each layer has its own responsibilities. The interface layer defines administrative and end-user interfaces. Users can access information via web browsers such as Microsoft Internet Explorer or Google Chrome. Administrators control and manage information via the web browser or using a separate server interface. The access layer provides system security and restricted access, firewall services, and system administration functions. The application layer defines various applications for analyzing and managing information. The database layer consists of a primary Microsoft SQL Server 2003 database. A firewall and virus scanning capability are used to protect the system database against intrusion.

The ConBIM-PM system is designed for all project BIM-related participants via a user-friendly portal, which serves as a real-time, on-line communication channel for project engineers. All data are stored and classified using the BIM management dashboard in the ConBIMPM system. Furthermore, the ConBIM-PM system is a solution that uses a single, unified database linked to the as-built models' files (DWF files) with different levels of access determined by user roles. Participants can access the BIM model PM information entry and updates, based on their responsibilities in the ConBIM-PM system. When information is updated in the ConBIMPM system, the server automatically sends e-mails and Really Simple Syndication (RSS) feeds to the project manager, BIM engineer, and the BIM manager associated with the issue. One purpose in this study is to extend BIM to the construction phase and create a single repository of interface data for all project engineers. The as-built model is applied in the ConBIM-PM system to capture and store as-built model information. The Autodesk Revit Architecture and Revit MEP were used

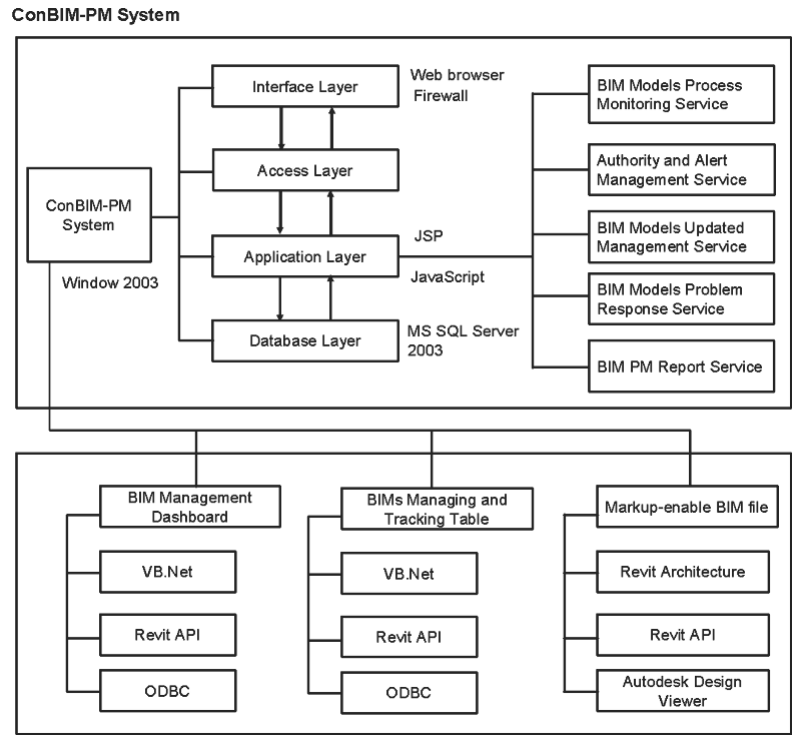

Fig. 3. Development framework of ConBIM-PM system 
to model the BIM management dashboard and create BIM files. The Autodesk Design Review was used to read as-built model files from the BIM management dashboard. Information integration with the BIM management dashboard was achieved using the Autodesk Revit application programming interface (API) and Microsoft Visual Basic.Net (VB.Net) programming language. The ConBIM-PM system was developed by integrating the BIM PM-related information using Autodesk Revit Architecture and Revit MEP software. All application programming interface (API) in the ConBIM-PM system were programmed in VB.Net using Revit API. A program in $\mathrm{C}++$ was written to integrate acquired data from different software programs and all interface information, such that as-built model files could be exported to an ODBC database for connection with the ConBIMPM system.

In order to keep the system performance the information derived by other applications should be stored in an external location. Therefore, there are two databases designed in the ConBIM-PM system: The BIM elements database and the BIMPM database. The BIM elements database only stores basic information (such as components of BIM position, ID and name of issues, and key parameter information of components), while the BIMPM database stores BIM PM information. The two databases are linked with element ID index thought data mapping. Therefore, the information can be utilized for data association by data mapping to retrieve complete problem information based on element ID index between two databases. In order to integrate system with the BIM model, the system develops the following two API modules. The first API module provides for import of basic information of selected BIM model into the editing form automatically without manual data entry when the user is ready to edit problems or comments and click BIM components in the as-built models. Another API module allows the user to save current viewing BIM model information submitted by users (such as view position, direction, elevation, and zoom information). When user enter the system and click the problem issue and then can quickly access the same $3 \mathrm{D}$ view position and direction for a clear PM-relevant understanding to BIM components in the as-built models.

\subsection{System modules}

This section demonstrates the implementation of ConBIMPM system modules.

\subsubsection{Authority management module}

The authority management module is an access control mechanism preventing unauthorized users from entering the system or retrieving sensitive as-built models information. The ConBIM-PM system requires all project engineers, project managers, BIM engineers, and BIM managers to register. To register, users provide a unique User ID and password for authentication. As BIM PM information and reports required by different project engineers and different BIM models vary, project engineers, BIM engineers and BIM managers will have different access rights and authorities from others.

\subsubsection{BIM processes monitoring module}

The BIM process monitoring module tracks BIM PM work. Additionally, project engineers and BIM engineers can access BIM-related information regarding the current process or versions of the as-built models. The process monitoring module has an easy access option that allows participants to track and record online the information and status of BIM PM. Furthermore, BIM engineers and project engineers can share the most recent revised asbuilt model files and information and access all current responses about problems with an as-built model from onsite project engineers.

\subsubsection{Alert Management module}

The Alert Management module helps the BIM manager, BIM engineers, and project engineers set up an alert service for monitoring and managing interfaces via e-mail and RSS feed. Dates related to notification of BIM version information are recorded systematically; thus, the BIM manager can determine who is responsible for specific BIM PM work. Furthermore, this module provides convenient access and a push-based function to help the $\mathrm{BIM}$ manager, BIM engineers, and project engineers respond to situations before BIM PM work is tracked and others respond.

\subsubsection{BIM Models Update Management module}

The BIM Models Update Management module lets users create and maintain the version information of asbuilt models, which is stored with corresponding as-built models in DWF files. Authorized records for modifying as-built models version information can be extracted and summarized for the BIM version summary. Furthermore, all BIM version summaries can be presented on the web or extracted using commercially available software such as Adobe Acrobat.

\subsubsection{BIM Models Problem Response module}

The module centralizes storage of all versions of as-built models in an online environment. This allows project engineers, BIM engineers, and the BIM manager to respond effectively from a central location to as-built models problems and provide a revised description of corresponding modified as-built models (DWF files). This module also allows BIM engineers to determine when and by whom DWF files have been accessed, downloaded, edited, or uploaded. Usually, the onsite project engineer can submit the change information of as-built models or submit the problem description of current as-built models to a BIM engineer through the module. Furthermore, the BIM-based RFI problems also communicate with each other through the module. 


\subsubsection{BIM PM Report module}

The module lets users easily access the brief modified history information of BIM PM regarding each modified as-built model. Authorized records for modifying as-built models can be extracted and summarized for the BIM version-related reports. Furthermore, all BIM PM reports can be presented on the web or extracted using commercially available software such as Microsoft Word and Acrobat PDF.

\section{Case study}

\subsection{Case description}

The following case involves a GC with sixteen years of experience in constructing office buildings in Taiwan. The construction phase of this office-building project also involves six subcontractors and seven suppliers. Furthermore, the GC wanted to take full advantage of using the BIM approach to enhance onsite construction management (such as interface management, visual discussion, and so on). Based on the GC's previous experience, there are serious problems with onsite updating of as-built models when the as-built models change. Therefore, the $\mathrm{GC}$ assigned project engineers, BIM engineers, and a BIM manager to utilize the ConBIM-PM system to solve the onsite updating problems during the construction phase. The ConBIM-PM system was utilized in the office-building project to verify its efficacy and demonstrate its BIM PM work effectiveness.

During the BIM Models Creation phase, all requirements and plans for the original as-built BIM model development were identified by responsible BIM engineers or the BIM manager during the construction phase. BIM engineers used Autodesk Revit Architecture or Revit MEP to create the as-built models. Furthermore, the summary sheet of as-built models edited by a BIM engineer included brief descriptions of the BIM model, and basic information of as-built models. All initial as-built models created by the BIM engineers were transferred to a markup-enabled BIM DWF file for the project engineer. Finally, this BIM engineer submitted the original as-built model and markup-enabled BIM DWF file to the ConBIM-PM system for approval. During the Proofing BIM Models phase, all original as-built models were confirmed and proofed by BIM managers before the original as-built models were published for related onsite project engineers. When the original as-built models were approved by the BIM manager, the system showed the most recent status and result for each as-built model. Furthermore, project engineers could access the related as-built BIM model (DWF file) directly by clicking the BIM DWF file in the ConBIM-PM system. All as-built models (DWF files) were stored in the central database to avoid redundancy.

During the Modifying BIM Models phase, two project engineers discussed interface problems by using as-built models through the ConBIM-PM system. They identified the BIM problems and mistakes of the original as built model and reported such to the BIM engineer. After the BIM engineer received the feedback through the ConBIM-PM system, the BIM engineer updated the modified as-built models according to the explanations and comments. Another BIM engineer used the ConBIM-PM system to discuss changed BIM feedback with the BIM engineer based on the comments. The onsite project engineer described the change information of the original as-built models and noted the markup changes in the BIM DWF file (including descriptions and documentation) provided by the mechanical and electrical engineers. Furthermore, all records of BIM work processes were saved and tracked continually. Requests not responded to or processed in the assigned time were tracked in red and pushed again by the ConBIM-PM system. Furthermore, BIM managers, BIM engineers, and related project engineers could track and manage all completed or processed BIM work during the modifying BIM models phase. The two electrical engineers began responding to the selected asbuilt models with comments and requests for as-built models modification needs. Furthermore, three mechanical engineers provided updated BIM comments and feedback and offered descriptions for the original as-built model. After the original as-built model was modified, numerous modified as-built models were updated and shared among all project engineers during the phase. Additionally, the project engineer who initially identified the numerous problems in the as-built models updated the feedback and comments for the original as-built models. This BIM engineer received feedback from the project engineer, modified the as-built models to solve problems, and updated the modified as-built models and information in the ConBIM-PM system. After receiving the modified as-built models and assistance from the BIM engineer or BIM manager, the project engineer solved the interface problems by using the newest version of the modified as-built models. Typically, the BIM manager used the ConBIM-PM system to request problem replies from responsible BIM engineers when the BIM manager found the related BIM problems.

During the Completing BIM Models phase, the BIM engineer submitted the modified as-built models. After the project engineer identified the entire as-built models process finished, the BIM engineer requested confirmation of the final modified as-constructed models closure. Finally, the project engineer confirmed the accuracy of the final modified as-constructed models based on asconstructed showing drawings. The BIM work status was updated in black in the BIM management dashboard of the ConBIM-PM system after the approval process was complete. A notice and report were then transmitted to the BIM manager, BIM engineers, and authorized project engineers via e-mail and RSS. Figure 4 shows BIM PM tracking and sharing in the ConBIM-PM system. Figure 5 shows the flowchart of the process used in the ConBIM-PM system. 


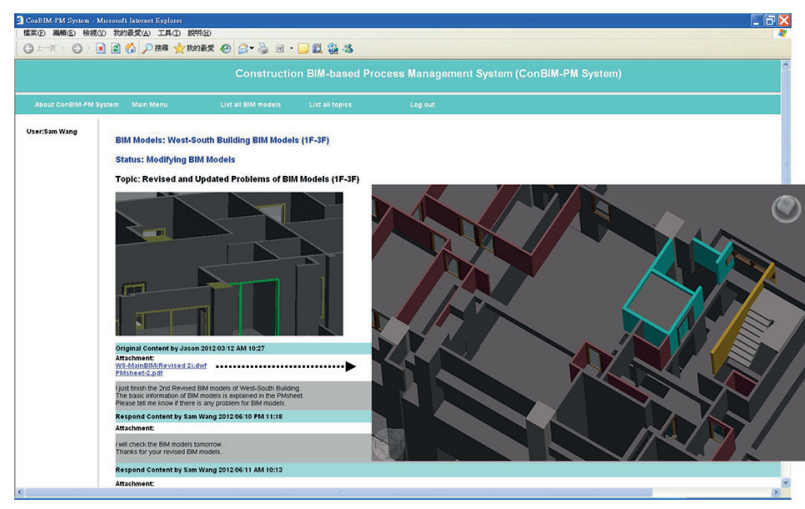

Fig. 4. BIM PM tracking and sharing in the ConBIM-PM system

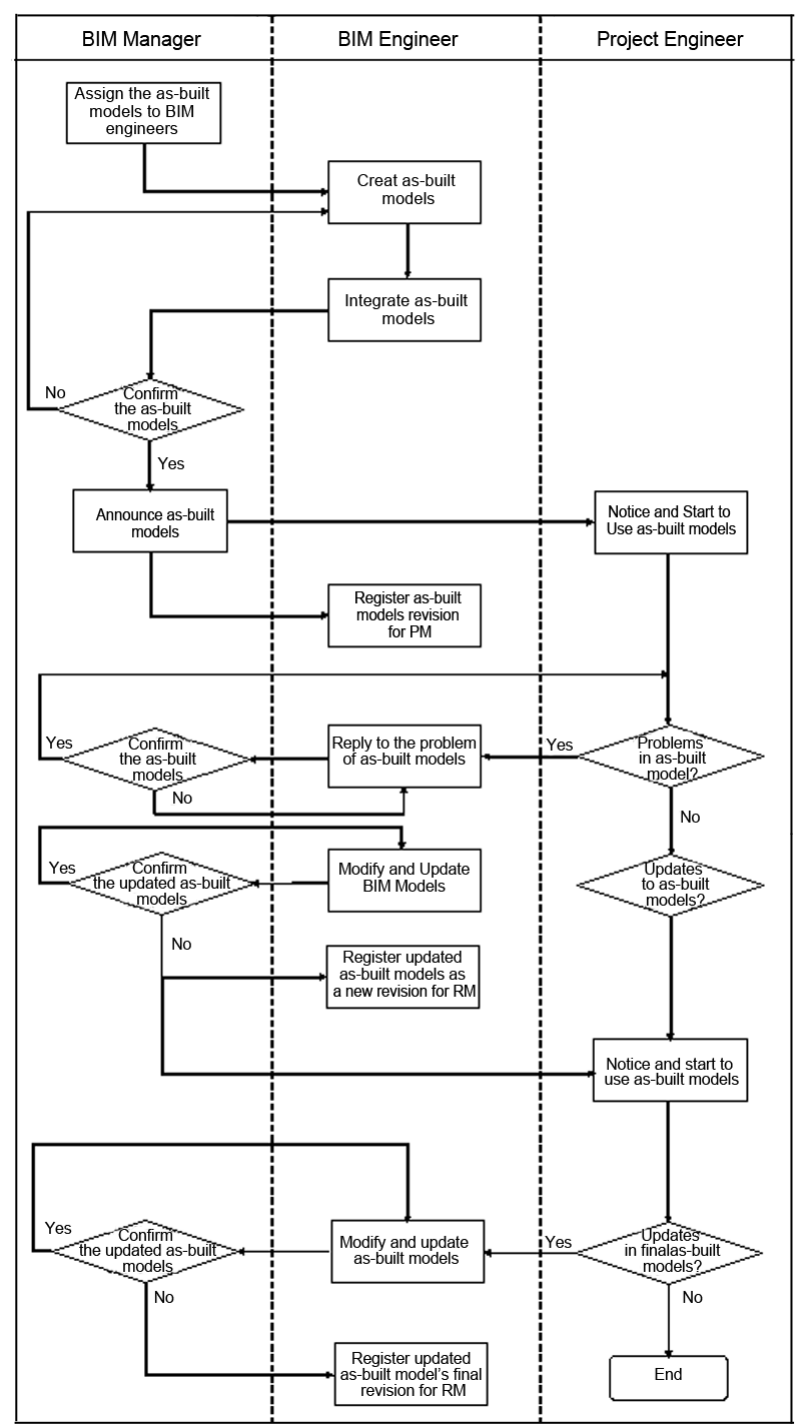

Fig. 5. The flowchart of the process used in the ConBIM-PM system

\subsection{Field tests and results}

The case study was a 5-month construction project with approximately 680 scheduled activities. During the field test, the BIM manager and three BIM engineers handled all the BIM works. The BIM works included the as-built models creation, modification, and revision. The six onsite project engineers with the general contractor handled the entire construction project through completion using the as-built models. The two mechanical, electrical, and plumbing subcontractors worked on building heating, cooling, and plumbing subprojects utilizing the BIM software. The ConBIM-PM system was installed on the general contractor's main server during the test. A user guide and two ConBIM-PM system workshops were held to demonstrate how to use the ConBIM-PM system integrated with BIM PM work. Furthermore, BIM software (Autodesk Revit Architecture and Autodesk Revit MEP) were selected to create and revise as-built models. A Design Web Format (DWF) file was selected as the format of BIM file for markup use. All BIM files were converted into DWF file for review and markup in the ConBIM-PM system. During the case study field testing, all researchers only assisted in the setup and usage of the ConBIM-PM system. All BIM work in the case study involved participants at the main office and jobsite, including a BIM manager, three BIM engineers, and project engineers. Of all the main issues and problems resolved using the ConBIM-PM system in the case project, 28 percent were issued with the as-built models new publish, 9 percent were mistakes in as-built models, 22 percent were issued with change version of the asbuilt models, 17 percent were issued with change feedback of the as-built models, and 24 percent were issued with RFI of the as-built models.

During the field test, verification and validation tests were performed to examine system function. The verification test determined whether the system operated correctly according to its design, while the validation test evaluated system utility. The verification test was performed by assessing whether the ConBIM-PM system performed tasks as specified in the system's design. During the validation test, selected case participants were asked to use the system; project teams then provided feedback via a questionnaire. The case participants consisted of three general contractor BIM engineers with two years' experience, one BIM manager with five years' experience, two senior subcontractor engineers with 10 years' experience, and six general contractor project engineers with six years' experience. Questionnaires were distributed to evaluate system function and user satisfaction with system capabilities. To verify the functionality and effectiveness of the ConBIM-PM system, there are three parts in the system evaluation. They are system functionality, system usage, and system capability. System users were asked to grade system functionality, usage, and capability separately, based on a comparison with the previous paper-based approach on a five-point Likert scale, ranging from 1 for "not useful" to 5 for "very useful." Questionnaire results indicate that BIM PM performance for GC during the construction phase was significantly improved by using the proposed system. Comments regarding possible improvements to the ConBIM-PM system were also obtained from project 
participants. The ConBIM-PM system was demonstrated to the respondents who were asked to express their opinions towards the system by completing the questionnaire. Table 3 shows the results of the system testing.

The following recommendations are based on user feedback: (1) successful BIM PM adoption should be supported by top management in a firm; (2) policy and strategy must be considered to encourage use of the ConBIM-PM system during the construction phase; (3) further effort is required to train project engineers using BIM software to mark up and annotate comments, information, and suggestions about revising as-built models; (4) further effort and additional approaches are required to overcome unwillingness to adopt BIM software at construction jobsite; (5) most senior engineers could not edit and mark up problems and comment on as-built models without assistance while typing; (6) initial case study results should be used to educate users about BIM software adoption, and additional staff training is needed; and (7) further training and workshops on the ConBIMPM system and BIM software are needed for all users.

Questionnaire results demonstrate that the primary advantages of the ConBIM-PM system are as follows:

Table 3. System evaluation result

\begin{tabular}{|c|c|}
\hline System functionality & Mean score \\
\hline Ease of interface sharing & 4.5 \\
\hline Reliability & 4.4 \\
\hline Applicability to construction industry & 4.8 \\
\hline System usage & Mean score \\
\hline Ease of use & 4.6 \\
\hline User interface & 4.5 \\
\hline Overall system usefulness & 4.3 \\
\hline System capability & Mean score \\
\hline $\begin{array}{l}\text { Reduces mistakes in as-built models } \\
\text { version }\end{array}$ & 4.2 \\
\hline Reduces rework percentage & 4.3 \\
\hline $\begin{array}{l}\text { Ease of finding as-built models } \\
\text { information }\end{array}$ & 4.7 \\
\hline $\begin{array}{l}\text { Improves responses to as-built models } \\
\text { problems }\end{array}$ & 4.5 \\
\hline $\begin{array}{l}\text { Improves BIM-based RFI } \\
\text { communication }\end{array}$ & 4.4 \\
\hline $\begin{array}{l}\text { Enhances updated as-built models } \\
\text { problems }\end{array}$ & 4.7 \\
\hline $\begin{array}{l}\text { Enhances as-built models version } \\
\text { tracking }\end{array}$ & 4.5 \\
\hline $\begin{array}{l}\text { Reduces the difference of as- } \\
\text { constructed models }\end{array}$ & 4.7 \\
\hline
\end{tabular}

Note: the mean score is calculated from respondents' feedback on fivescale questionnaire: 1 (Strongly Disagree), 2, 3, 4 and 5 (Strongly Agree).
(1) the BIM management dashboard provided clear visual representations facilitating identification of interface information and events related to 3D objects (93 percent agreed); (2) the BIM management dashboard clearly identified available interface information and events relevant to tasks (86 percent agreed); and (3) users tracked interface information and events easily and effectively with the BIM approach (94 percent agreed).

The ConBIM-PM system provided solutions to interface-related problems and supported all interfaces and changes during construction. The principal advantages of the ConBIM-PM system, based on questionnaire results, are as follows: (1) the ConBIM-PM system allowed BIM engineers and managers to track and manage BIM PM information during construction (93 percent agreed); (2) the ConBIM-PM system allowed project engineers to provide feedback on the errors and problems with asbuilt models through ConBIM-PM system (87 percent agreed); (3) the ConBIM-PM system enabled project engineers to track the newest version of as-built models and briefly view changes when using the as-built models ( 88 percent agreed); and (4) the ConBIM-PM system enhanced version and change management of as-built models easily and effectively in the web environment (90 percent agreed).

\subsection{Limitations and barriers}

User feedback indicated that the primary barriers to using the ConBIM-PM system were as follows: (1) most users were unsatisfied with the high disconnection rate and slow internet speed; (2) substantial amount of time and assistance were needed for engineers and managers to use BIM software to edit problems and update feedback on changed as-built models; (3) unwillingness of a few project engineers to update feedback on as-built models information; and (4) the file size of DWF directly affects the operation performance of the ConBIM-PM system.

The findings of this case study revealed several limitations of the ConBIM-PM system. The following are inherent problems recognized during the case study.

- It will be difficult for new users to operate the BIM model in the ConBIM-PM system. In the beginning, some project engineers were initially unfamiliar with as-built models. It usually takes time to learn the use of BIM models. In the case study, using the ConBIM-PM system initially took longer than the current approach to using as-built models. Project engineers required time to utilize the corresponding 3D as-built BIM models in the ConBIM-PM system. After the user was more skilled and familiar with utilizing as-built models, the time of comparison for the current approach and the proposed system in utilizing as-built models were almost the same.

- This study demonstrates that the ConBIM-PM system is an effective platform in supporting BIM PM work during the construction phase. However, onsite project engineers did not have sufficient time 
and assistance to edit and provide feedback on the change information of as-built models if they had a pressing schedule. Another problem was that not all involved project engineers had the same attitude regarding using the ConBIM-PM system to update as-built models. A few engineers were unwilling to edit and provide feedback on the BIM model change information to BIM engineers. The development of systems that satisfy all involved parties and the needs of the various project engineers depend on the different viewpoints and attitudes. Future research must address how a suitable mechanism can be integrated in the implementation of BIM work on jobsite.

- The feedback on the BIM model submitted by project engineers in the system lacked content and was typically incomplete, especially if project engineers were busy or had a tight schedule. Furthermore, the support of upper management is very important in the implementation of BIM work, especially in the jobsite. In the case study, overcoming the resistance of the project engineer, BIM engineers, and the BIM manager to using the BIM and ConBIM-PM system during their work was important. Overcoming this resistance has been regarded as one of the major prerequisites for the successful implementation of a ConBIM-PM system. Upper management implemented an incentive/bonus reward for using the ConBIM-PM system more consistently during the case study. Future research must address how a BIM work can be implemented onsite effectively and directly (including BIM model creation, modification, updating) in practice.

- Another problem is that the ConBIM-PM system can be used only on the construction site directly. The findings of the case study indicate that most project engineers edited their interfaces when they returned to the site office. However, based on the results of the case study, most project engineers agreed that editing problems and feedback on the as-built models at the jobsite using a smart phone or notebook in a Wi-Fi or $3 \mathrm{G}$ environment was inconvenient. Therefore, project engineers started to use tablet computers, such as iPads, for convenience. Case observations indicated that doing so improved the willingness of project engineers to apply the ConBIM-PM system and edit the BIM model directly at the jobsite.

- Because of the limited storage capacity of the PC and notebook, it is suggested that BIM engineers create the DWF files in the database in advance for referring to as-built models and handling the BIM PM work. However, the DWF file size will affect the operations performance of the ConBIM-PM system directly. The impact includes the time spent reading DWF files, the time spent searching for facilities, and the smoothness of system operations. When the
DWF file is too large (more than 100MB), it cannot be opened and easily read. Therefore, the original as-built models will be converted and separated into numerous DWF files. When the BIM engineer executes the BIM PM work, the ConBIM-PM system downloads only the DWF file and lets the project engineer refer to the separated DWF files quickly. The final limitation of the ConBIM-PM system is that BIM-related problem topics cannot be communicated and managed effectively based on objects of BIM models. Therefore, it is necessary and important to developing advanced BIM-based communication management systems for construction BIM work whose unit of management is objects rather than files. Doing so will be the goal of future work on ConBIM-PM system implementation.

- The top management support is very important for the successful implantation and adoption of BIM at the jobsite. Usually, most project engineers rely on the traditional 2D drawings to handle their jobsite work. To change project engineers' habits, suitable strategies and mechanisms need to be considered for successful BIM adoption by the general contractor. In this case study, the BIM work at the jobsite was highly supported by the jobsite manager. Therefore, most project engineers were encouraged to utilize the as-built model and use the ConBIM-PM system for construction management (such as interface management and communication).

- It is necessary and important for project engineers to trust the accuracy of the BIM model. Without the as-built model updating, most project engineers will prefer to refer to traditional $2 \mathrm{D}$ drawings and not use the as-built model. If project engineers don't trust the accuracy of the BIM model, project engineers will be unwilling to utilize the as-built model at the construction jobsite. Consequently, the practice implementation of BIM will fail without gaining the support from project engineers. Therefore, further efforts and additional strategies should be developed and executed for the successful implementation of BIM adoption at the jobsite.

\section{Conclusions}

The application of BIM integrated with the process management for building projects during the construction phase is discussed in this work. This study develops the novel ConBIM-PM system for all project participants as a BIM PM platform. Through a web-based environment, the ConBIM-PM system can provide project engineers with feedback on the updated content of as-built models or request the correction of problems with the asbuilt models through a markup-enabled DWF file. The ConBIM-PM system facilitates an updating approach and platform for as-built models based on project engineers' feedback and questionnaire responses. In order to assist the GC with implementing BIM work effectively, this 
study develops the ConBIM-PM system for engineers to enhance change information through BIM model sharing and tracking efficiency. By using the ConBIM-PM system, project engineers, and BIM engineers can maintain a clear audit trail by tracking version control and updates to as-built models for a given project. Furthermore, project participants can access and utilize the most recently updated as-built models for BIM application in practice during the construction phase. All as-built models can be updated, and changes and problems are available to each project engineer via the markup-enabled DWF file. The ConBIM-PM system is especially developed for the communication and process management of as-built models between main office and jobsite. The proposed enhancing management is different from the other existing BIM tools and software.

For the general contractor, most project engineers utilize as-built models directly at jobsites. In order to enhance performance of as-built models versions management between the main office and jobsite, this study proposes as-built models change management mechanism and as-built models feedback management mechanism for BIM PM work. The mechanism of as-built models change management includes the as-built models published announcement and process record of different as-built models versions. Furthermore, the mechanism of as-built models feedback management includes the process record of as-built models problem feedback from project engineers and process record of as-built models problem respond feedback from BIM engineers. The proposed ConBIM-PM system will be designed, developed, and integrated with the two mechanisms.

According to case study, the top management support is very important for the successful implantation of BIM at the jobsite. To change project engineers' habits, suitable strategies and mechanisms need to be considered for successful BIM adoption by the general contractor. Furthermore, project engineers will be unwilling to utilize the BIM model at the construction if project engineers don't trust the accuracy of the BIM model. Consequently, the practice implementation of BIM will fail without gaining the support from project engineers. Therefore, further efforts and additional strategies should be developed for the successful implementation of BIM adoption at the jobsite during the construction phase.

Finally, the proposed ConBIM-PM system is applied to a case study of a building project in Taiwan to verify its efficacy and demonstrate its BIM PM effectiveness. The case study results demonstrate that the ConBIM-PM system provides users with centralized storage of all versions of as-built models during the construction phase of a project, such that the BIM manager, BIM engineers, and project engineers can track and manage the status of modified as-built models and update asbuilt models effectively. The case study also highlights the need to improve onsite BIM PM work during the construction phase. Integrating web-based technologies and the BIM PM approach is promising for improving the problems of onsite BIM adoption during the construction phase. Overall, field test results indicate that the proposed ConBIM-PM system is an effective and user-friendly platform for $\mathrm{GC}$ to handle construction BIM PM work.

\section{Acknowledgement}

The authors would like to acknowledge the National Science Council, Taiwan, for financially supporting this work and express our appreciation to the D-W Construction Inc for assistance in the system design and interviews, and to the experts and engineers of the owner of the project for providing useful data, valuable information, and helpful comments during the system design and development.

\section{References}

Azhar, S. 2011. Building Information Modeling (BIM): trends, benefits, risks, and challenges for the AEC industry, Leadership and Management in Engineering 11(3): 241-252. http://dx.doi.org/10.1061/(ASCE)LM.1943-5630.0000127

Barlish, K.; Sullivan, K. 2012. How to measure the benefits of BIM-A case study approach, Automation in Construction 24: 605-613.

http://dx.doi.org/10.1016/j.autcon.2012.02.008

Becerik-Gerber, B.; Kensek, K. 2010. Building information modeling in architecture, engineering, and construction: emerging research directions and trends, Journal of Professional Issues in Engineering Education and Practice 136(3): 139-147.

http://dx.doi.org/10.1061/(ASCE)EI.1943-5541.0000023

Becerik-Gerber, B.; Rice, S. 2010. The perceived value of building information modeling in the US building industry, ITCON 15: 185-201 [online], [cited 20 May 2011]. Available from Internet:

http://www.itcon.org/data/works/att/2010_15.content.02423.pdf

Chau, K.; Anson, M.; Zhang, J. 2004. Four-dimensional visualization of construction scheduling and site utilization, Journal of Construction Engineering and Management 130 (4): 598-606.

http://dx.doi.org/10.1061/(ASCE)0733-9364(2004)130:4(598)

CRC for Construction Innovation 2010. Adopting BIM for facilities management: solutions for managing the Sydney opera house [online], [cited 28 March 2010]. Available from Internet: http://eprints.qut.edu.au/27582/1/27582.pdf

Ding, L. Y.; Zhou, Y.; Luo, H. B.; Wu, X. G. 2012. Using nD technology to develop an integrated construction management system for city rail transit construction, Automation in Construction 21(7): 64-73.

http://dx.doi.org/10.1016/j.autcon.2011.05.013

Dossick, C. S.; Neff, G. 2010. Organizational divisions in BIMenabled commercial construction, Journal of Construction Engineering and Management 136(4): 459-467. http://dx.doi.org/10.1061/(ASCE)CO.1943-7862.0000109

Eastman, C.; Teicholz, P.; Sacks, R.; Liston, K. 2008. BIM handbook: a guide to building information modeling for owners, managers, designers, engineers and contractors. Hoboken, NJ: Wiley. 490 p. http://dx.doi.org/10.1002/9780470261309

Eddy, K.; Bradley, N. 2008. Green BIM: successful sustainable design with building information modeling. Hoboken, NJ: Wiley. $241 \mathrm{p}$. 
Elbeltagi, E.; Dawood, M. 2011. Integrated visualized time control system for repetitive construction projects, Automation in Construction 20(7): 940-953. http://dx.doi.org/10.1016/j.autcon.2011.03.012

Fu, C.; Aouad, G.; Lee, A.; Ponting, A.; Wu, S. 2006. IFC model viewer to support $\mathrm{nD}$ model application, Automation in Construction 15(2): 178-185.

http://dx.doi.org/10.1016/j.autcon.2005.04.002

Goedert, J. D.; Meadati, A. G. F. 2008. Integrating construction process documentation into building information modeling, Journal of Construction Engineering and Management 134(7): 509-516.

http://dx.doi.org/10.1061/(ASCE)0733-9364(2008)134:7(509)

Gould, F.; Joyce, N. E. 2008. Construction project management. 3rd ed. New Jersey: Prentice Hall.

Hardin, B. 2009. BIM and construction management: proven tools, methods, and workflows. New Jersey: John Wiley \& Sons. 364 p.

Hartmann, T.; Meerveld, H. V.; Vossebeld, N.; Adriaanse, A. 2012. Aligning building information model tools and construction management methods, Automation in Construction 22: 605-613.

http://dx.doi.org/10.1016/j.autcon.2011.12.011

Jason, U.; Umit, I. 2010. Handbook of research on building information modeling and construction informatics: concepts and technologies. Hershey: IGI Global. 757 p.

Jung, Y.; Joo, M. 2011. Building information modelling (BIM) framework for practical implementation, Automation in Construction 20(2): 126-133. http://dx.doi.org/10.1016/j.autcon.2010.09.010

Kaner, I.; Sacks, R.; Kassian, W.; Quitt, T. 2008. Case studies of BIM adoption for precast concrete design by midsized structural engineering firms, ITCON 13: 303-323 [online], [cited 21 June 2011]. Available from Internet:

http://www.itcon.org/data/works/att/2008_21.content.09961.pdf

Klein, L.; Li, N.; Becerik-Gerber, B. 2012. Imaged-based verification of as-built documentation of operational buildings, Automation in Construction 21(1): 161-171. http://dx.doi.org/10.1016/j.autcon.2011.05.023

Lee, G.; Park, H. K.; Won, J. 2012a. D3 City project - economic impact of BIM-assisted design validation, Automation in Construction 22: 577-586. http://dx.doi.org/10.1016/j.autcon.2011.12.003

Lee, S. I.; Bae, J. S.; Cho, Y. S. 2012b. Efficiency analysis of set-based design with structural building information modeling (S-BIM) on high-rise building structures, Automation in Construction 23: 20-32. http://dx.doi.org/10.1016/j.autcon.2011.12.008

Lee, J. K.; Lee, J.; Jeong, Y.; Sheward, H.; Sanguinetti, P.; Abdelmohsen, S.; Eastman, C. M. 2012c. Development of space database for automated building design review systems, Automation in Construction 24: 203-212. http://dx.doi.org/10.1016/j.autcon.2012.03.002

Leite, F.; Akcamete, A.; Akinci, B.; Atasoy, G.; Kiziltas, S. 2011. Analysis of modeling effort and impact of different levels of detail in building information models, Automation in Construction 20(5): 601-609.

http://dx.doi.org/10.1016/j.autcon.2010.11.027

Li, G.; Ding, L.; Wang, J. 2006. Construction project control in virtual reality: a case study, Journal of Applied Science 3(13): 2724-2732.

Lin, W. D. 2010. Process problems in BIM work for general contractor in Taiwan construction projects, in Proc. of 2010 PM Conference, 2010, Taiwan, 131-136.

Manning, R.; Messner, J. 2008. Case studies in BIM implementation for programming of healthcare facilities, ITCON 13: 446-457 [online], [cited 27 March 2011]. Available from Internet:

http://www.itcon.org/data/works/att/2008_18.content.05339.pdf
Matta, C.; Kam, C. 2010. The GSA'sBIM Pilot Program, Presentation by GSA PBS Office of the Chief Architect [online], [cited 21 March 2010]. Available from Internet: http://bim.arch.gatech.edu/data/reference/gsaBIM.pdf

NBIMS. 2007. National building information modeling standard Part-1: overview, principles and methodologies. US National Institute of Building Sciences Facilities Information Council, BIM Committee [online], [cited 19 Sep 2011]. Available from Internet: http://www.wbdg.org/pdfs/NBIMSv1_p1.pdf

Redmond, A.; Hore, A.; Alshawi, M.; West, R. 2012. Exploring how information exchanges can be enhanced through Cloud BIM, Automation in Construction 24: 175-183. http://dx.doi.org/10.1016/j.autcon.2012.02.003

Ren, Y.; Skibniewski, M. J.; Jiang, S. 2012. Building information modeling integrated with electronic commerce material procurement and supplier performance management system, Journal of Civil Engineering and Management 18(5): 642-654. http://dx.doi.org/10.3846/13923730.2012.719835

Fox, S.; Hietanen, J. 2007. Interorganizational use of building information models: potential for automational informational and transformational effects, Construction Management and Economics 25: 289-296. http://dx.doi.org/10.1080/01446190600892995

Schlueter, A.; Thesseling, F. 2009. Building information model based energy/exergy performance assessment in early design stages, Automation in Construction 18(2): 153-163. http://dx.doi.org/10.1016/j.autcon.2008.07.003

Shen, W.; Shen, Q.; Sun, Q. 2012. Building information modeling-based user activity simulation and evaluation method for improving designer-user communications, Automation in Construction 21: 148-160.

http://dx.doi.org/10.1016/j.autcon.2011.05.022

Shen, Z.; Issa, R. 2010. Quantitative evaluation of the BIM assisted construction detailed cost estimates, ITCON 15: 234-257 [online], [cited 22 May 2011]. Available from Internet:

http://www.itcon.org/data/works/att/2010_18.content.07578.pdf

Shih, N. J. 1994. Managing construction drawing documents with an automatic index system, in The $11^{\text {th }}$ International Symposium on Automation and Robotics in Construction (ISARC), 24-26 May 1994, Brighton, United Kingdom, 547-554.

Staub-French, S.; Khanzode, A. 2007. 3D and 4D modeling for design and construction coordination: issues and lessons learned, ITCON 12: 381-407 [online], [cited 5 June 2011] Available from Internet:

http://www.itcon.org/data/works/att/2007_26.content.07145.pdf

Succar, B. 2009. Building information modelling framework: a research and delivery foundation for industry stakeholders, Automation in Construction 18(3): 357-375. http://dx.doi.org/10.1016/j.autcon.2008.10.003

Taylor, J. E.; Bernstein, P. G. 2009. Paradigm trajectories of building information modeling practice in project networks, Journal of Management in Engineering 25(2): 69-76.

http://dx.doi.org/10.1061/(ASCE)0742-597X(2009)25:2(69)

Tse, T. K.; Wong, K. A.; Wong, K. F. 2005. The utilisation of building information models in $\mathrm{nD}$ modelling: a study of data interfacing and adoption barriers, ITCON 10: 85-110 [online], [cited 16 May 2011] Available from Internet:

http://www.itcon.org/data/works/att/2005_8.content.05676.pdf

Umit, I.; Jason, U. 2010. Two design patterns for facilitating building information model-based synchronous collaboration, Automation in Construction 19(5): 544-553. http://dx.doi.org/10.1016/j.autcon.2009.11.006

Vanlande, R.; Nicolle, C.; Cruz, C. 2008. IFC and building lifecycle management, Automation in Construction 134(7): 70-78. http://dx.doi.org/10.1016/j.autcon.2008.05.001 
Xudong, Z.; Jie, T. 2007. Building information modeling based on intelligent parametric technology, Frontiers of Architecture and Civil Engineering in China 1(3): 367-370. http://dx.doi.org/10.1007/s11709-007-0049-4
Zhou, W.; Whyte, J.; Sacks, R. 2012. Construction safety and digital design: a review, Automation in Construction 22: $102-111$.

http://dx.doi.org/10.1016/j.autcon.2011.07.005

Yu-Cheng LIN. Associate Professor of construction engineering and management at the Dept of Civil Engineering of the National Taipei University of Technology. He received the M.S. degree in the construction management program of civil engineering from the Polytechnic University, New York, USA and received PhD degree from the National Taiwan University in Taiwan (2004). His current research interests include construction knowledge management, project interface management, building information modeling, web-based project management system, IT technology application, automation, BIM related topics. He has published several articles and papers on the role of academic support service in computer-based construction project management.

Hsin-Yun LEE. He is earned his PhD at National Chiao Tung University, Taiwan. He is Associate Professor of Civil Engineering at National Ilan University, Taiwan. His present areas of research include renovation and maintenance of infrastructure, scheduling, engineering optimization, simulation, and layout.

I-Tung YANG. Professor and Vice Chairman in the Department of Construction Engineering at National Taiwan University of Science and Technology (Taiwan Tech). He obtained PhD in Civil Engineering from the University of Michigan, Ann Arbor, in 2002. Dr. Yang's research deals with development and application of computational intelligence methods in solving civil engineering problems. His research interests also include construction management, simulation optimization \& decision making, and life cycle engineering. 